\title{
PALANDELLA (Liliane), Vive le parascolaire! Entre l'école et la famille à Genève depuis 1886.
}

Genève : GIAP, 2006, 239 p. et ill.

Pierre-Philippe Bugnard

\section{OpenEdition}

\section{Journals}

Édition électronique

URL : https://journals.openedition.org/histoire-education/617

DOI : 10.4000/histoire-education.617

ISSN : 2102-5452

Éditeur

ENS Éditions

Édition imprimée

Date de publication : 1 janvier 2008

Pagination : 148-150

ISBN : 978-2-7342-1113-6

ISSN : 0221-6280

\section{Référence électronique}

Pierre-Philippe Bugnard, «PALANDELLA (Liliane), Vive le parascolaire! Entre l'école et la famille à Genève depuis 1886. », Histoire de l'éducation [En ligne], 117 | 2008, mis en ligne le 20 octobre 2008, consulté le 20 mai 2021. URL : http://journals.openedition.org/histoire-education/617 ; DOI : https://doi.org/ 10.4000/histoire-education.617

Ce document a été généré automatiquement le 20 mai 2021.

(ㄷ) Tous droits réservés 


\section{PALANDELLA (Liliane), Vive le parascolaire! Entre l'école et la famille à Genève depuis 1886.}

Genève : GIAP, 2006, 239 p. et ill.

\section{Pierre-Philippe Bugnard}

\section{RÉFÉRENCE}

PALANDELLA (Liliane),Vive le parascolaire! Entre l'école et la famille à Genève depuis 1886. Genève : GIAP, 2006, 239 p. et ill.

1 Se rend-on assez compte des immenses services que rendent à Genève, depuis plus de 120 ans, les activités liées à l'accueil des enfants à midi et après l'école? Voilà un système sans doute propre à cette ville (certes, encore faudrait-il le montrer), la France connaissant la « halte garderie ", créée au début du XX ${ }^{\mathrm{e}}$ siècle pour les plus petits avec un accueil sans enseignement, et la " salle d'asile ", établie sous la monarchie de Juillet pour assurer soins et première éducation jusqu'à sept ans, ancêtre des écoles maternelles actuelles, fondées en 1881. La spécificité genevoise est donc peut-être dans la nécessité de créer des institutions prenant en charge les enfants en dehors des heures de classe durant pratiquement toute la scolarité obligatoire, et aussi avant l'âge de l'école, cette dernière n'assumant pas elle-même une telle fonction.

2 Il reste qu'à Genève, la prise en charge parascolaire des enfants suit l'évolution des conceptions éducatives de celui des systèmes scolaires suisses qui s'apparente sans doute le plus à l'école républicaine française. Le besoin d'une prise en charge des enfants naît de la conjonction de l'obligation scolaire (établie en 1872 à Genève), de l'interdiction du travail en fabrique (1877) et d'une phase dure de l'industrialisation au cours de laquelle les enfants restent sans repas à midi et sont livrés à eux-mêmes après 16 heures, la mère ayant souvent rejoint le père à l'atelier. Les députés abandonnent d'abord la création - et la dépense - des «classes gardiennes » aux communes (entre la 
fin du XIX ${ }^{e}$ siècle et celle du siècle suivant, elles passeront à l'État cantonal, avant de revenir aux communes); le privé, par l'intermédiaire des milieux philanthropiques, complète l'offre avec les « cuisines ou pensions scolaires ».

"Ouvrir une école, c'est fermer une prison » : l'adage hugolien indique parfaitement l'accent mis dès les débuts sur l'instruction, la surveillance et la moralisation des " couches flottantes» d'écoliers issus des classes pauvres, des plus petits aux adolescents de 14 ans, avec des objectifs qui se déplacent au cours du siècle vers l'animation, les activités ludiques et sportives. Dans la foulée des «palais scolaires » de la Belle époque, qui scellent l'image d'une école triomphante, on sent la marque de l'État cantonal, qui prend le relais des communes pour donner à l'instruction publique les moyens du progrès jusqu'au plus profond des réfectoires, où sont déjà servis 70000 repas par an avant la Grande Guerre.

4 À partir de là, on peut suivre, au travers d'une riche documentation, l'histoire d'un «parascolaire» tour à tour victime ou bénéficiaire des conjonctures au cours d'un long siècle de crises et d'avancées accompagnant l'essor des loisirs, autour des questions matérielles, du bénévolat et des subventionnements, des menus, de la discipline et de l'animation, des études surveillées, des enjeux de la démocratisation scolaire...

5 Il y a donc jusqu'à nos jours, en fonction de cette double mission du parascolaire de nourrir et d'éduquer entre les heures de classe, deux histoires distinctes à suivre : celle des classes gardiennes, surtout grâce aux archives publiques de l'État et du Département de l'instruction publique genevois, sollicitées dans un travail de bénédictin où tout ce qui aurait pu être démontré, pratiquement, l'a été ; quant aux cuisines et aux restaurants scolaires, leur activité a pu être retracée, patiemment, au travers des relations qu'ils ont entretenues avec les autorités et par le biais de précieuses archives privées. Face à la masse documentaire, le choix a été de suivre en particulier, successivement, deux institutions témoins : la cuisine scolaire des Pâquis, créée en 1887 au cœur du célèbre quartier populaire de ce nom, ainsi que les restaurants scolaires des Asters et de Saint-Jean, ouverts en 1977 par un groupe de parents dans un autre quartier emblématique, celui de la Servette. On sent palpiter Genève dans ces pages trempées au quotidien de l'histoire scolaire.

\section{AUTEURS}

PIERRE-PHILIPPE BUGNARD 